\title{
Cefixime and Metals Complex Interaction: A systemic review on Drug-metals interaction
}

\section{Farzana Yesmin ${ }^{1}$ and Md. Shahidul Islam ${ }^{*}$}

${ }^{1}$ Department of Pharmacy, University of Science and Technology Chittagong (USTC), Chattogram, Bangladesh.

*Corresponding Author: Md. Shahidul Islam, Assistant Professor, Department of Pharmacy, University of Science \& Technology Chittagong (USTC), Chattogram, Bangladesh.

Received date: September 06, 2020; Accepted date: September 09, 2020; Published date: October 05, 2020

Citation: Yesmin F., Islam S., (2020) Cefixime and Metals Complex Interaction: A systemic review on Drug-metals interaction J, Pharmaceutics and Pharmacology Research 3(1); DOI: 10.31579/2693-7247013

Copyright: (C) 2020, Shahidul Islam, This is an open access article distributed under the Creative Commons Attribution License, which permits unrestricted use, distribution, and reproduction in any medium, provided the original work is properly cited.

\begin{abstract}
The review study work comprises of interaction studies of cefixime with different group of drugs and metals to know about the alteration in pharmacological activity of cefixime by other drugs or vice versa. Cefixime is included among the cephalosporin third generation drug class which is active against a wide range of Gram positive and Gram negative bacteria. Since the presence of different therapeutic class of drugs like cefixime may affect the bioavailability as well as pharmacokinetics of other drugs and metal in the blood or tissues, therefore in order to study the potential interaction of cefixime with different therapeutic class of drugs and metals which can show several type of toxicity or may develop drug resistance in the body is the main reason to perform this study. About 102 articles were screened from different databases related to Cefixime and its interaction for this review. This review study claims that there is a possible interaction between cefixime and other drugs\& metals which are confirmed by different method like GLC, HPLC, and Disk Diffusion Method. Drug resistance and unwanted adverse drug reactions are a common thing for different underlying factors which becomes an alarming issue. That's why this is significant.
\end{abstract}

Keywords: cefixime, review, interaction, analgesic and cognitive activities

\section{Introduction}

A drug interaction is a situation in which a substance affects the activity of a drug when both are administered together. This action can be synergistic or antagonistic or a new effect can be produced that neither produces on its own. Typically, interactions between drugs come to mind. However, interactions may also exist between drugs and foods as well as drugs and medicinal plants or herbs [1]. People taking anti depressant drugs such as monoamine oxidize inhibitors should not take food containing tyramine as hypertensive crisis may occur. These interactions may occur out of accidental misuse or due to lack of knowledge about the active ingredients involved in the relevant substances [2]. It is therefore easy to see the importance of these pharmacological interactions in the practice of medicine. If a patient is taking two drugs and one of them increases the effect of the other it is possible that an overdose may occur. The interaction of the two drugs may also increase the risk that side effects will occur [3]. On the other hand, if the action of a drug is reduced it may cease to have any therapeutic use because of under dosage. Notwithstanding the above, on occasion these interactions may be sought in order to obtain an improved therapeutic effect. Examples of this include the use of codeine with paracetamol to increase its analgesic effect or the combination of clavulanic acid with amoxicillin in order to overcome bacterial resistance to the antibiotic [4]. It should also be remembered that there are interactions that, from a theoretical standpoint, may occur but in clinical practice have no important repercussions [5]. The pharmaceutical interactions that are of special interest to the practice of medicine are primarily those that have negative effects for an organism. The risk that a pharmacological interaction will appear increases as a function of the number of drugs administered to a patient at the same time. Over a third $(36 \%)$ of older adults in the U.S. regularly use 5 or more medications or supplements and $15 \%$ are potentially at risk for a major drug-drug interaction. ${ }^{[4]}$ Both the use of medications and subsequent adverse drug interactions have increased significantly between 2005-2011 [6]. It is possible that an interaction will occur between a drug and another substance present in the organism. Or in certain specific situations a drug may even react with itself, such as occurs with dehydration. In other situations, the interaction does not involve any effect on the drug. In certain cases, the presence of a drug in an individual's blood may affect certain types of laboratory analysis [7]. It is also possible for interactions to occur outside an organism before administration of the drugs has taken place. This can occur when two drugs are mixed, for example, in a saline solution prior to intravenous injection. Some classic examples of this type of interaction include that thiopentone and suxamethonium should not be placed in the same syringe and same is true for benzylpenicillin and heparin. These situations will all be discussed under the same heading due to their conceptual similarity [8]. Cefixime is a third generation cephalosporin, it has a broad spectrum anti-bacterial activity, it has a bunch of indication as well as it shows different interactive too. For this mechanism or activity, it gives some unwanted activity of its own or towards other drugs which can form a resistance of its own which is not desirable.

\section{Methodology}

The whole methodology of the review study about this topic is divided into 2 basic parst. These parts are given below- 
Exploration of data and information about Cefixime and its interaction with other drugs: As Cefixime is an oral antibiotic which belongs from third generation of Cephalosporin's family, there were a lot of journal as well as article which are related with Cefixime. So, I had to follow these steps for a better and standard result about finding the interactive effects of cefixime and its related journal.

A. Searching of Cefixime related articles from different database like PubMed, Google scholar.

B. Selection of Cefixime related articles.

C. Screening of Cefixime and its interaction related articles.

D. Substraction of Cefixime's interaction related less important articles.

E. Extended Study of Cefixime's interaction related data and articles.

F. Emission of slightly significant interaction related journal of Cefixime.

G. Final selection of Cefixime's interaction related journals and abbreviated study about Cefixime's interactive effects with other drugs and metals.

Searching of Cefixime related articles from different database like PubMed, Google scholar: It has been searched around 160 articles through different journal, PubMed, Google Scholar, Science Direct which were related with Cefixime and its different effect.

Selection of Cefixime related articles: Then It has been selected 140 articles which were related with cefixime and excluded 20 duplicate articles among them.

Screening of Cefixime and its interaction related articles: After selection of Cefixime related articles from different database it has been emitted 25 more articles from previously selected 160 articles for better conception and analysis of Cefixime and its interactive effect.
Substraction of Cefixime's interaction related less important articles: After choosing 135 articles, it has been excluded 12 more articles which were less related with Cefixime's interactive effect. By this way, selection was done in a standard way.

Extended Study of Cefixime's interaction related data and articles: As the use of Cefixime is in a broad spectrum for its availability, there were a lots of articles of Cefixime. The extended study about 123 articles of Cefixime was done for a better understanding.

Emission of slightly significant interaction related journal of Cefixime: It has been excluded 26 more articles which were less significant for the cefixime and its interactive effect.

Final selection of Cefixime' $s$ interaction related journals and abbreviated study about Cefixime' $s$ interactive effects with other drugs and metals: Cefixime is a broad spectrum oral antibiotic, for that reason it is used for the treatment of different types of Gram positive and Gram negative bacteria. As it is used in several bacterial infection's treatment, its interactive effect can be observed with other drugs and metals. It has been studied about 95 journal which were related with Cefixime and tried to know about its interactive effect briefly.

After performing these steps it has been choosen some vital cases of Cefixime's interaction with other drugs and metals.

Duration of Data Exploration: It has been explored these data and information from 04.07.2020 to 31.08.2020 and able to collect these data and information about interactive effect of Cefixime with different drugs and metal. The final outcome will be explained here about the interaction of cefixime.

\section{Results and Discussion}

\begin{tabular}{|c|c|c|c|}
\hline $\begin{array}{l}\text { Dose of } \\
\text { Cefixime }\end{array}$ & Comparator Drug/Metal & $\begin{array}{l}\text { Therapeutic Class of Comparator } \\
\text { Drug }\end{array}$ & Interaction Identification \\
\hline $400 \mathrm{mg}$ & $\begin{array}{l}\text { Diclofenac sodium, Flurbiprofen, } \\
\text { Mefenamic acid and Tiaprofenic acid }\end{array}$ & NSAIDs & $\begin{array}{l}\text { UV visible spectrophotometer } \\
\text { [9] }\end{array}$ \\
\hline $\begin{array}{l}0.086 \mathrm{gm} \text { of } \\
\text { standard }\end{array}$ & Copper, Zinc \& Cadmium Complexes & Metal & $\begin{array}{l}\text { Disk diffusion Method } \\
{[10]}\end{array}$ \\
\hline $400 \mathrm{mg} / \mathrm{kg}$ & Metformin & $\begin{array}{l}\text { Anti hyperglycemic agent of the } \\
\text { biguanide class }\end{array}$ & Rehberry Method [10] \\
\hline $400 \mathrm{mg}$ & Omeprazole,Rosuvastatin,Clopidogrel & $\begin{array}{l}\text { Omeprazole-proton pump inhibitor, } \\
\text { Rosuvastatin- } \\
\text { antihyperlipidemicdrug,Clopidogrel- } \\
\text { anti-platelet drug. }\end{array}$ & RP-HPLCMethod [11] \\
\hline $200 \mathrm{mg}$ & Carbamazepine - Levetiracetam & $\begin{array}{l}\text { Carbamazepine Anticonvulsant } \\
\text { Levetiracetam- Anticonvulsant. }\end{array}$ & EEG [12] \\
\hline $400 \mathrm{mg}$ & Nebviolol & Anti-hypertensive & LC-MS Method [12] \\
\hline $400 \mathrm{mg}$ & Bestatin & Protease inhibitor & LC-MS/MS analysis [13] \\
\hline $200 \mathrm{mg}$ & Vitamin K1 & Vitamin & GLC Method [13] \\
\hline
\end{tabular}

Table 1: Interactive effect of Cefixime with different therapeutic drugs and metals.

These are the results which are enlisted from the screened journal about the interactive effect of Cefixime with other drugs and metals.

Drug resistance and its unwanted interactive effects can be avoided if few measures can be taken properly [14]. They are-

Track the resistance frequency. Local, national and global surveillance systems of drug susceptibility would help to communicate the current status of resistance in a location, facilitating more appropriate choices of treatment. Such surveillance would alert public health officials to new pathogens and would spur the implementation of control policies.

By isolating hospitalized individuals with potentially dangerous resistant bacteria.

By introducing new therapeutic approaches: Confronted with a shortage of new antimicrobials, we must use our current drugs more prudently. Reducing and improving use can diminish resistance and 
permit a drug to resurface eventually as an effective therapy58. The appropriate use of the antibiotics not only can help to reverse high resistance frequencies, but also can curb the appearance of resistance to newer agents.

By choosing the appropriate drug class for appropriate disease condition: Choice and prescribing the appropriate drug class and regimen plays an important role for diminishing the drug resistance possibility. So the health care professionals and patient both should be extra cautious in case of prescribing and administering drugs.

\section{Conclusion}

Drug Interaction occurs for mainly the pharmacological, therapeutical alternation of a drug towards another drug or by vice versa. Cefixime like third generation Cephalosporin which is a broad spectrum antibiotic is used for the treatment of the bacterial infection caused by Gram positive and Gram negative bacterial both. So, there is a huge possibility of interaction between Cefixime and other drugs which are administered for multiple therapy. For this reason, toxicity as well as multiple drug resistance occurs with unwanted effects which can cause deterioration of a patient's health. For this reason, the main purpose of serving medical treatment is being interrupted which is undesirable. From this review study there are several findings I have got which are so vital and can help the health care professionals along with general population in case of prescribing and administering these drugs concomitantly. Cefixime interacts with glucose in rats when it is co administered with metformin in rats. Cefixime interacts with Copper, Zinc, and Cadmium and decrease the anti-microbial activity of it. Cefixime interact with omeprazole, rovustatin, clopidogrel and changes its own activity. Cefixime can induce non convulsive epilepticus. Cefixime can increase the plasma blood concentration of NSAIDs as well as can alter the actual expected activity. Cefixime can interacts with anti-hypertensive drugs and change its plasma concentration which can produce unwanted toxicity. So, these combination of drugs shouldn't be administered concomitantly for ensuring a better health care system.

\section{References}

1. Veber DF, Johnson SR, Cheng HY, Smith BR, Ward KW, Kopple KD. (2002) Molecular properties that influence the oral bioavailability of drug candidates. Journal of medicinal chemistry; 45(12):2615-23.

2. Riechelmann RP, Moreira F, Smaletz Ò, Saad ED. (2005) Potential for drug interactions in hospitalized cancer patients. Cancer chemotherapy and pharmacology; 56(3):286-90.
3. Saad AH, DePestel DD, Carver PL. (2006) Factors influencing the magnitude and clinical significance of drug interactions between azole antifungals and select immunosuppressants. Pharmacotherapy: The Journal of Human Pharmacology and Drug Therapy; 26(12):1730-44.

4. Faulkner RD, Yacobi AV, Barone JS, Kaplan SA, Silber BM. (1987) Pharmacokinetic profile of cefixime in man. The Pediatric infectious disease journal; 6(10):963-70.

5. Knapp CC, Sierra-Madero JU, Washington JA. (1988) Antibacterial activities of cefpodoxime, cefixime, and ceftriaxone. Antimicrobial agents and chemotherapy; 32(12): 1896-8.

6. Ali T, Mohiuddin OA. (2012) In vitro interaction study of cefixime with diclofenac sodium, flurbiprofen, mefenamic acid and tiaprofenic acid. J Chem Pharm Res; 4(6):2911-8.

7. Arayne MS, Sultana NA, Khanum FO, Ali MA. (2002) Antibacterial studies of cefixime copper, zinc and cadmium complexes. Pakistan Journal of Pharmaceutical Sciences; 15(1):18.

8. Anzellotti F, Ricciardi L, Monaco D, Ciccocioppo F, Borrelli I, et al. (2012) Cefixime-induced nonconvulsive status epilepticus. Neurological Sciences; 33(2):325-9.

9. Venkateswarlu B, Jayaprakash D, Anisetti R, Narsaiah N, Reddy MR. (2013) Effect of cefixime on pharmacokinetics of nebivolol in hypertensive patients. International Journal of Pharmaceutical Sciences and Research; 4(11):4362

10. Capparelli FJ, Diaz MF, Hlavnika A, Wainsztein NA, Leiguarda R, Del Castillo ME. (2005) Cefepime-and cefixime-induced encephalopathy in a patient with normal renal function. Neurology; 65(11):1840-3.

11. Wang L, Wang C, Liu Q, Meng Q, Huo X, et al. (2014) PEPT1and OAT1/3-mediated drug-drug interactions between bestatin and cefixime in vivo and in vitro in rats, and in vitro in human. European Journal of Pharmaceutical Sciences; 63:77-86.

12. Neu HC, Chick TW. (1993) Efficacy and safety of clarithromycin compared to cefixime as outpatient treatment of lower respiratory tract infections. Chest; 104(5):13939.

13. Boudignat O, Zylbertrest T, Roche G. (1990) Comparative study of two dosage regimens of cefixime in the treatment of upper or lower respiratory infections. Drugs of Today; 26(Suppl 10):21-23

14. Beskid G, Christenson J, Cleeland R, DeLorenzo W, Trown P. (1981) In vivo activity of ceftriaxone (Ro 13-9904), a new broadspectrum semisynthetic cephalosporin.Antimicrobial agents and chemotherapy; 20: 159-67.

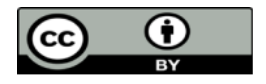

This work is licensed under Creative Commons Attribution 4.0 License

To Submit Your Article Click Here: Submit Article

DOI: $10.31579 / 2693-7247013$

\author{
Ready to submit your research? Choose Auctores and benefit from: \\ * fast, convenient online submission \\ * rigorous peer review by experienced research in your field \\ * rapid publication on acceptance \\ * authors retain copyrights \\ * unique DOI for all articles \\ * immediate, unrestricted online access
}

At Auctores, research is always in progress.

Learn more www.auctoresonline.org/journals/pharmaceutics-andpharmacology-research 